\title{
Lifetime risk and projected population prevalence of diabetes
}

\author{
D. J. Magliano • J. E. Shaw • S. M. Shortreed • \\ W. J. Nusselder • D. Liew • E. L. M. Barr • \\ P. Z. Zimmet • A. Peeters
}

Received: 18 May 2008 / Accepted: 7 August 2008 / Published online: 23 September 2008

(C) Springer-Verlag 2008

\begin{abstract}
Aims/hypothesis With incidence rates for diabetes increasing rapidly worldwide, estimates of the magnitude of the impact on population health are required. We aimed to estimate the lifetime risk of diabetes, the number of years lived free of, and the number of years lived with diabetes for the Australian adult population from the year 2000, and to project prevalence of diabetes to the year 2025 .

Methods Multi-state life-tables were constructed to simulate the progress of a cohort of 25-year-old Australians. National mortality rates were combined with incidence rates of diabetes and the RR of mortality in people with diabetes derived from the Australian Diabetes, Obesity and Lifestyle study (a national, population-based study of 11,247 adults aged $\geq 25$ years).

Results If the rates of mortality and diabetes incidence observed over the period 2000-2005 continue, 38.0\% (95\%
\end{abstract}

D. J. Magliano $(\bowtie) \cdot$ J. E. Shaw $\cdot$ E. L. M. Barr · P. Z. Zimmet

Baker IDI Heart and Diabetes Research Institute,

250 Kooyong Road,

Caulfield, VIC 3162, Australia

e-mail: dianna.magliano@bakeridi.edu.au

D. J. Magliano $\cdot$ S. M. Shortreed $\cdot$ A. Peeters

Department of Epidemiology and Preventive Medicine,

Monash University,

Melbourne, VIC, Australia

W. J. Nusselder

Department of Public Health, Erasmus MC,

Rotterdam, The Netherlands

D. Liew

Department of Medicine, The University of Melbourne,

St Vincent's Hospital,

Fitzroy, VIC, Australia uncertainty interval 36.6-38.9) of 25-year-olds would be expected to develop diabetes at some time throughout their life. On average, a 25-year-old Australian will live a further 56 years, 48 of these free of diabetes. On average, a 45year-old person with diabetes can expect to live 6 years less than a person free of diabetes. The prevalence of diabetes is projected to rise from $7.6 \%$ in 2000 to $11.4 \%$ by 2025 .

Conclusions/interpretation If we maintain current diabetes incidence rates, more than a third of individuals will develop diabetes within their lifetime and in Australia there will an additional 1 million cases of diabetes by the year 2025 .

Keywords Diabetes · Epidemiology Incidence .

Life expectancy $\cdot$ Lifetime risk $\cdot$ Mortality Population .

Prevalence

$\begin{array}{ll}\text { Abbreviations } \\ \text { 2hPG } & 2 \mathrm{~h} \text { plasma glucose } \\ \text { AusDiab } & \text { Australian Diabetes, Obesity and Lifestyle } \\ & \text { study } \\ \text { FPG } & \text { fasting plasma glucose } \\ \text { NDI } & \text { National Death Index } \\ \text { UI } & \text { uncertainty interval }\end{array}$

\section{Introduction}

Diabetes is a significant health problem worldwide. In 2007, there were 246 million people living with diabetes [1]. In Australia the prevalence of diabetes doubled between 1981 and 2000 [2] and is expected to increase further as a result of population ageing, urbanisation and increasing obesity rates [1]. To expand the understanding of the burden of diabetes, life-table modelling techniques can 
use incidence, prevalence and mortality data to estimate the lifetime risk of diabetes, the life expectancy of those with diabetes, and the future prevalence of diabetes. This important assessment of disease burden has only been undertaken in two related studies, in the USA [3, 4]. However, these studies used incidence rates that were based on self-reporting of physician-diagnosed diabetes, rather than rates based on blood glucose measurements. Furthermore, the generalisability of these findings to countries with a less advanced obesity epidemic and different ethnic make-up is limited.

It has been estimated by the WHO and the International Diabetes Federation that the prevalence of diabetes worldwide will double by the year $2030[1,5]$. However, these projections are not based on current incidence and mortality rates and do not take into account future epidemiological trends. Here we undertake the most comprehensive analyses of this kind. The aim of this study was to estimate the lifetime risk, life expectancy and burden of diabetes in the coming decades, using data from the Australian Diabetes, Obesity and Lifestyle (AusDiab) study, and national mortality data. A key strength of the AusDiab study is that diabetes is defined using the OGTT.

\section{Methods}

Sample population and measurements The AusDiab baseline study methods have been reported previously $[6,7]$. In brief, AusDiab was a cross-sectional, national, populationbased survey of 11,247 adults aged $\geq 25$ years in 19992000 , comprising a household interview and biomedical examination at a testing site. Over $85 \%$ of the sample was born in Australia, New Zealand or the UK, and over 94\% spoke English as their first language; $0.8 \%$ were of Aboriginal or Torres Strait Islander background. The response rate to the baseline biomedical examination among those who completed a household questionnaire was $55.3 \%$. In 2004-2005, all participants $(n=11,247)$ were invited to attend a follow-up examination. Those who refused further contact $(n=128)$, were deceased $(n=310)$, had moved overseas or into a nursing facility classified for high-care, or had developed a terminal illness $(n=21)$ were considered ineligible. Of the 10,788 participants eligible for testing in 2004-2005, 6,537 (60.6\%) presented for the biomedical examination and/or blood tests.

In this study, mortality rates (in those with and without diabetes) were estimated among participants whose diabetes status could be classified at baseline and whose vital status could be determined at follow-up $(n=11,075)$. Among this group, 942 had diabetes at baseline. Incidence was derived from 5,842 participants who were diabetes-free at baseline and returned for follow-up.
At baseline and follow-up, questionnaires were administered, anthropometric measurements were taken and a fasting blood sample was collected. All participants underwent a $75 \mathrm{~g}$ OGTT [8] (those with treated diabetes or who were pregnant were excluded). The reliability of glucose measurement is reported elsewhere [6, 7]. Glucose tolerance status was classified according to WHO criteria [8]. Diabetes was diagnosed on the basis of fasting plasma glucose (FPG) of $\geq 7.0 \mathrm{mmol} / 1$ or $2 \mathrm{~h}$ plasma glucose ( $2 \mathrm{hPG}$ ) of $\geq 11.1 \mathrm{mmol} / 1$ or current treatment with insulin and/or oral hypoglycaemic agents. The study was approved by the ethics committee of the International Diabetes Institute, all participants provided informed consent, and approval for matching the AusDiab cohort to the National Death Index (NDI) was granted by the Australian Institute of Health and Welfare.

Vital status in AusDiab was assessed annually by linking the AusDiab $(n=11,247)$ cohort to the Australian NDI [9]. People who were not matched to the NDI were assumed to be alive. This study included all deaths $(n=348)$ up until 1 June 2005 occurring among participants whose diabetes status could be classified at baseline and whose vital status could be determined at follow-up.

Life-table models Multi-state life-tables were constructed with two alive states (no diabetes and diabetes). These models are based on three sets of age-specific transition rates: (1) incidence of diabetes; (2) all-cause mortality in those without diabetes; and (3) all-cause mortality in those with diabetes. These life-tables simulate the annual progression of a cohort of 25-year-olds free of diabetes in the year 2000 and followed until death or age 100 years. Analyses were performed for the total population, and for men and women, using sex-specific incidence and mortality rates. Life-tables were constructed in Microsoft Excel 2007.

Diabetes incidence rates The incidence of diabetes was calculated as the number of new cases of diabetes divided by the total person-years from the population free of diabetes at baseline. The date of diabetes diagnosis was estimated as the midpoint between baseline and follow-up testing dates. Age-specific incidence rates were estimated using Poisson regression, including single year of age and age squared in the model. Sex-specific incidence rates were estimated by including a sex term into the model. (All coefficients are available upon request.) An additional analysis was undertaken to account for the possible overestimation of diabetes incidence associated with the use of a single OGTT. The incidence rates in this additional analysis were adjusted by decreasing the proportion of newly diagnosed incident cases by $37.3 \%$, which was the 
proportion of those individuals who had newly diagnosed diabetes according to FPG and $2 \mathrm{hPG}$ at baseline, but who did not have diabetes at the 5 year follow-up.

All-cause mortality rates The age and state-specific allcause mortality rates were derived by combining national all-cause mortality data with diabetes prevalence rates and RRs of mortality from the AusDiab study. The national allcause mortality data were provided by the Human Mortality Database for the year 2002 [10]. The crude single year of age-specific prevalence of diabetes was estimated from the AusDiab study. Age-specific RRs of mortality associated with diabetes were derived by dividing the smoothed mortality rates of those with and without diabetes. These smoothed age-specific mortality rates were estimated using Poisson regression, including single year of age in the model. The all-cause mortality rate for the population without diabetes $\left(\mu_{\mathrm{ND}}\right)$ and the all-cause mortality rate for the population with diabetes $\left(\mu_{\mathrm{D}}\right)$ were then calculated using the following formula: $\mu=\left[\mu_{\mathrm{ND}} \times(1-p)\right]+\left[\mu_{\mathrm{ND}} \times\right.$ $\mathrm{RR} \times p$ ], where $\mu$ is the all-cause mortality rate for the total population, RR is the RR of all-cause mortality in the population with diabetes relative to the population without diabetes, and $p$ is the prevalence of diabetes. This was performed for each single year of age. For the sex-specific analyses, sex-specific prevalences and mortality rates were used. However, because of the small number of deaths in those with diabetes, total population rather than sex-specific RRs were used.

Static multi-state life-tables Static multi-state life-tables were constructed, assuming that the diabetes incidence and all-cause mortality rates in those without diabetes and in those with diabetes had reached a steady-state [11, 12]. These life-tables represent a cohort of 25-year-olds free of diabetes in the year 2000 exposed to the incidence and mortality observed between 2000-2005, throughout their entire future lifetime (75 years). Residual lifetime risk of diabetes, average years of life lived free of diabetes, and average years of life lived with diabetes were derived.

Static multi-state life-tables were also constructed for a cohort of people with diabetes. These life-tables comprised only two states: alive with diabetes and dead. Age-specific mortality rates for the population with diabetes, derived as described above, were applied. Residual life expectancy and loss of life expectancy compared with those free of diabetes were estimated from these life-tables.

Dynamic multi-state life-tables Dynamic multi-state lifetable models were created to analyse the future population impact of the current diabetes incidence and mortality rates between the year 2000 and 2025. In essence, the dynamic models are a series of linked multi-state life-tables, one for each year between 2000 and 2025. In these linked lifetables, the population at a given age $(a)$ and time $(t)$ depend on the population at age $(a-1)$ and time $(t-1)$ and on the incidence of diabetes and the associated mortality between $(t-1)$ and $(t)$. The baseline multi-state life-table population, representing the population age structure in Australia in the year 2000 was created by applying age-specific population numbers for the year 2000 [13], and the age-specific prevalence of diabetes observed in AusDiab [2], to the static life-table structure described above. With each passing year, a new cohort of 25 -year-olds entered the model, based on population projections between 2008 and 2025 from the Australian Bureau of Statistics [14], and assuming the same constant prevalence of diabetes at age 25. From these dynamic models, age-specific and total prevalence of diabetes were derived for each year between 2000 and 2025.

Temporal trends Scenario analyses were performed in which temporal trends for incidence and mortality rates were applied. The mortality rate in both the population with and without diabetes was assumed to decrease by $2.2 \%$ per year, reflecting the average decrease in allcause mortality rates in Australia between 2000 and 2004 [15]. Diabetes incidence rates were assumed to increase by $20 \%$ every 5 years $[16,17]$. This increase was chosen as it lies between published increases in diabetes incidence reported in Canada of $15 \%$ [16] and in the USA of $25 \%$ [17] over 5 years. All trends were applied from the year 2005 until the year 2025 after which time rates were held constant. Additional scenario analyses were performed to examine alternative increases in diabetes incidence rates of $10 \%$ or $30 \%$ over 5 years. These temporal trends were applied to both the static and dynamic multi-state life-tables.

Uncertainty intervals Ninety-five per cent uncertainty intervals (UIs) around lifetime risk were derived by analysing the impact of each of the key inputs using @ RISK Version 4.5.7 Professional Edition (Palisade, Ithaca, NY, USA). @ RISK is a software macro add-on for Microsoft Excel that performs Monte Carlo simulation. With this method, inputs are entered as ranges rather than single values and each range is described by a probability distribution (triangular) to reflect the nature of uncertainty [18]. In these analyses, the inputs for the @ RISK simulation were the point estimates and $95 \%$ CIs for the following inputs: age-specific diabetes incidence rates, diabetes prevalence and the RR for mortality associated with diabetes. The CIs of these inputs were calculated using 1,000 bootstrap samples of the AusDiab dataset. 
Table 1 Diabetes incidence over 5 years, prevalence of diabetes in 1999-2000 and mortality risk in the AusDiab study

Values in parentheses are $95 \%$ CIs

${ }^{\text {a }}$ Participants who could not be allocated a diabetes status or whose vital status could not be confirmed at follow-up were excluded

${ }^{\mathrm{b}} 6,537$ participants were followed up at 5 years; 5,842 of these were at risk of diabetes

\begin{tabular}{lll}
\hline Characteristic & Men & Women \\
\hline$n$ at baseline & & 6,061 \\
Age, years (mean \pm SD) & 5,014 & $51.4 \pm 14.5$ \\
Number without diabetes & $51.9 \pm 14.3$ & 5,616 \\
Number with diabetes & 4,517 & 445 \\
Prevalence of diabetes at baseline (\%) & 497 & $7.3(6.7-8.0)$ \\
Number of deaths in those without diabetes & $9.9(9.1-10.7)$ & 104 \\
Number of deaths in those with diabetes & 149 & 37 \\
RR of mortality in diabetic population & 58 & $4.6(3.2-6.7)$ \\
Number of incident cases of diabetes & $3.7(2.7-5.0)$ & 109 \\
Number at risk of diabetes & 115 & 3,200 \\
Five year incidence of diabetes (\%) & 2,642 & 3.4 \\
\hline
\end{tabular}

\section{Results}

Table 1 shows that after 5 years follow-up in AusDiab, there were 224 new cases of diabetes among the 5,842 individuals free of diabetes at baseline. In the baseline cohort $(n=11,075)$, there were 95 deaths among the 942 with diabetes and 253 deaths among the 10,133 without diabetes. The overall crude incidence rate of diabetes was 7.8 (95\% CI 6.8-8.9) per 1,000 person-years. The crude RR of death associated with having diabetes was 4.2 (95\% CI $3.3-5.3$ ), ranging from 6.4 at age 25 years to 1.1 at age 95 years

Lifetime risk In the primary analysis, in which mortality and diabetes rates were assumed to be constant over time, $38.0 \%$ of the 25-year-old Australians in 2000 were predicted to develop diabetes at some time throughout their life, with 22.2\% developing it before age 65 (Table 2). For men and women, the lifetime probabilities of developing diabetes were $39.9 \%$ (95\% UI 38.6-41.1) and 36.7\% (95\% UI 35.0-37.8), respectively. If incidence rates were reduced to allow for potential overdiagnosis of diabetes using a single OGTT, the lifetime risk of diabetes for the total population was estimated to be $29.9 \%$. When incidence rates were projected to increase by $20 \%$ over 5 years and mortality rates were assumed to decrease at $2.2 \%$ per year up until the year 2025, the lifetime risk of diabetes was estimated to be $66.6 \%$ (Table 3 ). If diabetes incidence was assumed to increase by $10 \%$ or by $30 \%$, the lifetime risks were $63.9 \%$ and $94.7 \%$, respectively.

Life expectancy Based on current incidence and mortality rates, an average 25-year-old Australian in 2000 could expect to live $14 \%$ of their remaining 56 years with diabetes. For men, life expectancy from 25 years was a further 54 years with 8 of these years spent with diabetes. For women, life expectancy from 25 years is 58 years, eight of these spent with diabetes. If falling mortality and increasing incidence are projected until the year 2025, life expectancy is predicted to increase marginally to 82.5 years. However, the remaining years of life lived with diabetes would almost double to 16 years (27\%) (Fig. 1).

A 45-year-old person with diabetes would be predicted to live 6 years less than a person free of diabetes at age 45 , and 7 years less than a 45 -year-old who remained diabetesfree throughout life (Table 4).

Population projections In the year 2000, the modelled prevalence of diabetes in Australians aged $\geq 25$ years was $7.6 \%$. This differs slightly from previously published
Table 2 Lifetime probability (\% of cohort) of developing diabetes using current incidence and mortality rates held constant for the life of the cohort

Data refer to the percentage of a cohort of 25-year-olds initially free of diabetes (relative to initial $n=100$ )

${ }^{a}$ The cumulative incidence of diabetes represents the proportion of the original cohort that has ever had diabetes by the given age

\begin{tabular}{lllll}
\hline \multirow{2}{*}{ Age (years) } & Alive (\%) & & Dead (\%) & $\begin{array}{l}\text { Cumulative incidence of diabetes } \\
\%(95 \% \text { UI) }\end{array}$ \\
\cline { 2 - 3 } & Free of diabetes & With diabetes & & \\
\hline 25 & 100.0 & 0.0 & 0.0 & 0.0 \\
45 & 90.9 & 7.1 & 2.0 & $7.4(6.8-7.8)$ \\
55 & 82.3 & 13.1 & 4.6 & $14.1(13.5-14.6)$ \\
65 & 70.2 & 19.2 & 10.8 & $22.2(21.6-22.7)$ \\
75 & 53.4 & 20.8 & 25.8 & $30.0(29.3-30.6)$ \\
85 & 29.3 & 13.6 & 57.1 & $35.5(34.3-36.3)$ \\
100 & 1.6 & 0.9 & 97.5 & $38.0(36.6-38.9)$ \\
\hline
\end{tabular}


estimates of diabetes prevalence of $7.4 \%$, which is weighted to the age and sex distribution of the 1998 estimated residential population $[2,6]$. Assuming that the incidence and mortality rates observed between 2000 and 2005 remained constant, the prevalence of diabetes in the year 2025 among Australians aged $\geq 25$ years would be $11.4 \%$ (Table 5). However, assuming falling mortality and increasing diabetes incidence, the prevalence of diabetes in the year 2025 would be $17.0 \%$ (Table 6). If the 5 year increase in incidence of diabetes were $10.0 \%$ or $30.0 \%$, the population prevalences would be $15.4 \%$ and $24.0 \%$, respectively.

Because of changes in both population structure and the continuation of current diabetes incidence trends, the number of Australians aged $\geq 25$ years with diabetes would be predicted to increase from about 950,000 in 2000 to about 2 million in 2025. Assuming increases in diabetes incidence and decreases in all-cause mortality, this number would be expected to reach about 2.9 million in 2025 .

\section{Discussion}

This study predicts that more than a third of today's young adults will develop diabetes during their lifetime, and that $14 \%$ of their remaining life will be lived with diabetes. Furthermore, the prevalence of diabetes among adults is expected to increase from $7.6 \%$ to $11.4 \%$ by the year 2025 . These estimates are based on new data derived from a large contemporary population-based national study, as well as data obtained from population mortality rates. These findings assume that the incidence and mortality rates observed between 2000 and 2005 remain constant over

Table 3 Lifetime probability (\% of cohort) of developing diabetes using incidence and mortality rates based on trends projected to 2025

\begin{tabular}{|c|c|c|c|c|}
\hline \multirow{2}{*}{$\begin{array}{l}\text { Age } \\
\text { (years) }\end{array}$} & \multicolumn{2}{|c|}{ Alive (\%) } & \multirow[t]{2}{*}{ Dead (\%) } & \multirow{2}{*}{$\begin{array}{l}\text { Cumulative incidence } \\
\text { of diabetes }{ }^{\mathrm{a}}(\%)\end{array}$} \\
\hline & $\begin{array}{l}\text { Free of } \\
\text { diabetes }\end{array}$ & $\begin{array}{l}\text { With } \\
\text { diabetes }\end{array}$ & & \\
\hline 25 & 100.0 & 0.0 & 0.0 & 0.0 \\
\hline 45 & 88.2 & 9.9 & 1.9 & 10.2 \\
\hline 55 & 72.7 & 23.2 & 4.1 & 24.4 \\
\hline 65 & 53.7 & 36.5 & 9.8 & 40.9 \\
\hline 75 & 35.3 & 41.2 & 23.5 & 54.6 \\
\hline 85 & 18.5 & 30.9 & 50.6 & 63.0 \\
\hline 100 & 1.7 & 3.9 & 94.4 & 66.6 \\
\hline
\end{tabular}

Data refer to the percentage of a cohort of 25-year-olds initially free of diabetes (relative to initial $n=100$ )

${ }^{\mathrm{a}}$ The cumulative incidence of diabetes represents the proportion of the original cohort that has ever had diabetes by the given age.

Mortality rates adjusted by applying a decline of $2.2 \%$ per year. Diabetes incidence rates adjusted by applying an increase of $20 \%$ every 5 years from the year 2005 to the year 2025, after which time rates were kept constant

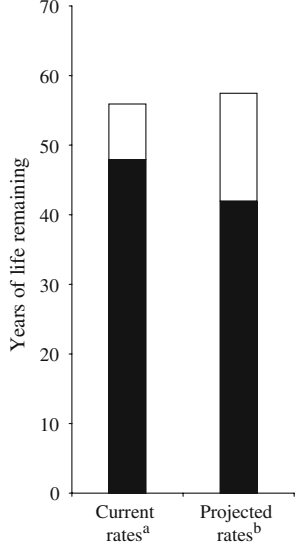

Fig. 1 Life expectancy free of diabetes and with diabetes from age 25 years. White areas of columns, the average years lived with diabetes; black areas, average years lived free of diabetes. ${ }^{\mathrm{a}}$ Rates from 2000-2005 held constant until 2075. ${ }^{b}$ Rates based on projected increases in diabetes incidence (20\% every 5 years) and decreases in mortality at $2.2 \%$ per year from the year 2005 until the year 2025 , after which rates were kept constant

time. If recently observed trends in both all-cause mortality and diabetes incidence rates were to continue until the year 2025 , then approximately two-thirds of all adults would be predicted to develop diabetes over a lifetime, and the prevalence of diabetes in those $\geq 25$ years will increase to $17.0 \%$ by 2025 . Given recent trends in obesity, such analyses taking into account increasing diabetes incidence rates may well be more realistic.

As expected, life expectancy of those with diabetes was shown to be lower than those without diabetes. In this population with diabetes, remaining life expectancy from age 45 was reduced by approximately one-quarter compared with a population remaining diabetes-free throughout life. These losses are less than those predicted by Narayan et al. [3], by whom non-Hispanic white males and females aged 50 were predicted to lose 8.8 and 11.8 years, respectively. This is probably because of a number of differences between the studies, including differences in the populations used in each study, such as differences in access to healthcare and levels of obesity, differences in the definition of diabetes, and differences in the years from which the RRs of mortality in those with diabetes were derived.

Work of a similar nature is restricted to only two other studies, from the USA [3, 19]. Narayan et al. [3, 19] provided estimates of lifetime risk and life expectancy in the USA. However, this study had two key limitations. First, diabetes status was ascertained via self-reporting, which may lead to an underestimation of true diabetes incidence and prevalence rates. Second, incidence rates, RRs of mortality and mortality rates were derived from different sources [3]. In contrast, our analysis uses diabetes incidence rates and $\mathrm{RR}$ of mortality associated with 
Table 4 Life expectancy of people with diabetes

\begin{tabular}{|c|c|c|c|}
\hline \multirow{2}{*}{$\begin{array}{l}\text { Age } \\
\text { (years) }\end{array}$} & \multirow{2}{*}{$\begin{array}{l}\text { Remaining life } \\
\text { expectancy (years) }\end{array}$} & \multicolumn{2}{|l|}{ Years of life lost } \\
\hline & & $\begin{array}{l}\text { Compared with those without } \\
\text { diabetes at the same age } \mathrm{e}^{\mathrm{a}}\end{array}$ & $\begin{array}{l}\text { Compared with those without } \\
\text { diabetes over a lifetime }^{\mathrm{b}}\end{array}$ \\
\hline \multicolumn{4}{|c|}{ Total population } \\
\hline 25 & 48.3 & 7.6 & 9.2 \\
\hline 35 & 40.1 & 6.4 & 7.8 \\
\hline 45 & 31.7 & 5.5 & 6.6 \\
\hline 55 & 23.8 & 4.5 & 5.3 \\
\hline 65 & 16.5 & 3.5 & 3.9 \\
\hline \multicolumn{4}{|l|}{ Men } \\
\hline 25 & 45.4 & 8.2 & 10.0 \\
\hline 35 & 37.6 & 6.7 & 8.3 \\
\hline 45 & 29.5 & 5.6 & 6.9 \\
\hline 55 & 21.7 & 4.6 & 5.5 \\
\hline 65 & 14.6 & 3.5 & 4.0 \\
\hline \multicolumn{4}{|l|}{ Women } \\
\hline 25 & 51.8 & 6.3 & 7.6 \\
\hline 35 & 42.8 & 5.6 & 6.8 \\
\hline 45 & 34.0 & 4.9 & 5.9 \\
\hline 55 & 25.7 & 4.1 & 4.8 \\
\hline 65 & 18.1 & 3.1 & 3.4 \\
\hline
\end{tabular}

${ }^{\mathrm{a}}$ Comparison of a person with diabetes with a person without diabetes at the same age but who may get diabetes at some time later

${ }^{\mathrm{b}}$ Comparison of a person with diabetes with a person who remains without diabetes throughout life available for the current analysis) and the $20 \%$ who completed only a telephone questionnaire [7]. It is unlikely that differences in the remaining $20 \%$ would have materially affected the estimates of diabetes incidence for the whole population. In addition, the observed incidence rates are very similar to diabetes incidence data from other national cohort studies in Italy [22] and not much lower than diabetes incidence in Spain [23] or that reported from a cohort of older Australians from the Blue Mountains Eye Study [24].

The second potential limitation is the use of a single OGTT to define diabetes in this study, since clinical diagnosis of diabetes requires confirmation on another day [8]. When the estimates were adjusted for the proportion of individuals who had blood glucose levels in the diabetic range at baseline, but not at the 5 year follow-up, the lifetime risk of diabetes decreased to $30 \%$. However, two

Table 5 Projected prevalence of diabetes from 2000 to 2025 using current incidence and mortality rates held constant for the life of the cohort and all-cause mortality and in population changes over time.

One of the key limitations of the present study is the potential selection bias of the AusDiab study, owing to the exclusion of individuals not living in residential homes (e.g. prisoners, hospitalised patients and people residing in nursing homes), the healthy volunteer bias, and the $55 \%$ and $61 \%$ response rates at the first and second survey, respectively. Loss to follow-up may mean that the diabetes incidence rates are not wholly reflective of population incidence rates. However, previous analysis has shown that self-reported diabetes incidence was very similar in the $60 \%$ who participated fully in the follow-up (and were

\begin{tabular}{lrrrrrr}
\hline Population & \multicolumn{7}{l}{ Prevalence (\%) } & & & \\
\cline { 2 - 7 } & 2000 & 2005 & 2010 & 2015 & 2020 & 2025 \\
\hline $\begin{array}{l}\text { Total population } \\
\text { Age (years) }\end{array}$ & 7.6 & 8.6 & 9.4 & 10.1 & 10.8 & 11.4 \\
25-44 & 1.3 & 2.6 & 2.9 & 3.2 & 3.1 & 3.1 \\
$45-64$ & 8.7 & 9.3 & 10.6 & 11.5 & 12.3 & 13.1 \\
$65-84$ & 19.3 & 20.7 & 19.9 & 19.8 & 20.6 & 20.9 \\
\hline
\end{tabular}

Diabetes incidence and mortality rates from 2000 to 2005 are kept constant until 2025 
Table 6 Projected prevalence of diabetes from 2000 to 2025 using incidence and mortality rates based on trends projected to $2025^{\mathrm{a}}$

\begin{tabular}{|c|c|c|c|c|c|c|}
\hline \multirow[t]{2}{*}{ Population } & \multicolumn{6}{|c|}{ Prevalence $(\%)$} \\
\hline & 2000 & 2005 & 2010 & 2015 & 2020 & 2025 \\
\hline Total population & 7.6 & 8.6 & 10.1 & 12.1 & 14.3 & 17.0 \\
\hline \multicolumn{7}{|l|}{ Age (years) } \\
\hline $25-44$ & 1.3 & 2.4 & 3.0 & 3.9 & 4.5 & 5.4 \\
\hline $45-64$ & 8.7 & 9.7 & 11.5 & 13.6 & 16.1 & 19.3 \\
\hline $65-84$ & 19.3 & 20.7 & 21.2 & 22.9 & 26.2 & 29.6 \\
\hline
\end{tabular}

${ }^{a}$ Mortality rates adjusted by applying a decline of $2.2 \%$ per year. Diabetes incidence rates adjusted by applying an increase of $20 \%$ every 5 years. Projections applied from the year 2005 to the year 2025, after which time rates were kept constant

reports have demonstrated the reproducibility of newly diagnosed diabetes according to the WHO criteria based on a single OGTT compared with two OGTT measurements to be $77 \%$ [25] and $78 \%$ [26], which is substantially higher than that assumed in our adjusted analyses (62.7\%). Consequently, we expect the analyses with adjusted incidence rates to underestimate the true risk.

It is important to recognise that the lifetime risk of disease presented here is that for a cohort of homogeneous individuals, representing an average person in the population. For any individual, the actual risk of developing diabetes throughout life will be affected by his or her unique combination of risk factors. In addition, it must be noted that projections can only ever be our best guess. Population health is not static and improvements in healthcare will have varying effects on the prevalence of diabetes. Improvements in diabetes care and treatment will increase survival for people with diabetes, and hence increase the prevalence of diabetes, while improvements in health behaviour and prevention will decrease both the incidence and prevalence of diabetes.

To put these results in context, it is useful to compare the lifetime risk of diabetes with other diseases. The risk of acquiring cardiovascular disease before the age of 85 years, using Framingham heart study data from the 1950s, was reported at $63 \%$ and $49 \%$ for 40 -year-old men and women, respectively [27]. The lifetime risks of breast and prostate cancer have been reported as 13\% [28] and 6\% [29], respectively.

The analyses presented here predict that there will be approximately 1 million more cases of diabetes in Australia by the year 2025. This is a conservative estimate, as it assumes no further increases in the incidence of diabetes over the next two decades. If current rates continue to rise, we predict a further million cases by the year 2025. These figures should provide the impetus for governing bodies to allocate the appropriate resources to the management of diabetes, to invest in diabetes research, and develop prevention strategies to minimise the impact of the growing diabetes epidemic.
Acknowledgements The AusDiab study, coordinated by the Baker IDI Heart and Diabetes Institute, gratefully acknowledges the generous support given by: the National Health and Medical Research Council (NHMRC grant 233200); Australian Government Department of Health and Ageing; Abbott Australasia Pty; Alphapharm Pty; AstraZeneca; Aventis Pharma; Bristol-Myers Squibb; City Health Centre (Diabetes Service) Canberra; Department of Health and Community Services, Northern Territory; Department of Health and Human Services, Tasmania; Department of Health, New South Wales; Department of Health, Western Australia; Department of Health, South Australia; Department of Human Services,Victoria; Diabetes Australia; Diabetes Australia, Northern Territory; Eli Lilly Australia; Estate of the late Edward Wilson; GlaxoSmithKline; the Jack Brockhoff Foundation; Janssen-Cilag; Kidney Health Australia; the Marian \& FH Flack Trust; the Menzies Research Institute; Merck Sharp \& Dohme; Novartis Pharmaceuticals; Novo Nordisk Pharmaceuticals; Pfizer Pty; the Pratt Foundation; Queensland Health; Roche Diagnostics Australia; Royal Prince Alfred Hospital, Sydney; and Sanofi Synthelabo. Also, we thank our study staff and study participants for their hard work and cooperation. A. Peeters was supported by a VicHealth Public Health Fellowship. Thanks also to B. Carstensen (statistician, The Steno Institute, Denmark), M. de Courten (Associate Professor, Department of Epidemiology and Preventive Medicine, Monash University) and H. Mannan (statistician, Department of Epidemiology and Preventive Medicine, Monash University) for constructive criticism of the work.

Duality of interest statement The authors declare that there is no duality of interest associated with this manuscript.

Role of the funding sources The sponsors had no role in the study design, or in the collection, analysis and interpretation of the data, or in the writing of this report, or in the decision to submit the paper for publication.

\section{References}

1. Sicree RA, Shaw JE, Zimmet PZ (2006) Diabetes and impaired glucose tolerance. In: Gan D (ed) Diabetes Atlas, 3rd Edition. International Diabetes Federation, Belgium, pp 15-105

2. Dunstan DW, Zimmet PZ, Welborn TA et al (2002) The rising prevalence of diabetes and impaired glucose tolerance: the Australian Diabetes, Obesity and Lifestyle Study. Diabetes Care 25:829-834 
3. Narayan KM, Boyle JP, Thompson TJ, Sorensen SW, Williamson DF (2003) Lifetime risk for diabetes mellitus in the United States. JAMA 290:1884-1890

4. Narayan KM, Boyle JP, Geiss LS, Saaddine JB, Thompson TJ (2006) Impact of recent increase in incidence on future diabetes burden: US, 2005-2050. Diabetes Care 29:2114-2116

5. Wild S, Roglic G, Green A, Sicree R, King H (2004) Global prevalence of diabetes: estimates for the year 2000 and projections for 2030. Diabetes Care 27:1047-1053

6. Dunstan DW, Zimmet PZ, Welborn TA et al (2002) The Australian Diabetes, Obesity and Lifestyle Study (AusDiab) methods and response rates. Diabetes Res Clin Pract 57:119-129

7. Magliano DJ, Barr EL, Zimmet PZ et al (2008) Glucose indices, health behaviors, and incidence of diabetes in Australia: the Australian Diabetes, Obesity and Lifestyle Study. Diabetes Care $31: 267-272$

8. World Health Organization (1999) Definition, Diagnosis and Classification of Diabetes Mellitus and its Complications; Part 1: Diagnosis and Classification of Diabetes Mellitus. World Health Organization, Geneva

9. Barr EL, Zimmet PZ, Welborn TA et al (2007) Risk of cardiovascular and all-cause mortality in individuals with diabetes mellitus, impaired fasting glucose, and impaired glucose tolerance: the Australian Diabetes, Obesity, and Lifestyle Study (AusDiab). Circulation 116:151-157

10. Human Mortality Database (2007) University of California BU and Max Planck Institute for Demographic Research (Germany). Available from http://www.mortality.org or www.humanmortality. de, accessed 10 June 2007

11. Nusselder WJ, Peeters A (2006) Successful aging: measuring the years lived with functional loss. J Epidemiol Community Health 60:448-455

12. Schoen R (1988) Modelling Multi-group Populations. Plenum Press, New York

13. Australian Bureau of Statistics (2000) Population by Age and Sex, Australia. Companion Data. Australian Bureau of Statistics, Canberra

14. Australian Bureau of Statistics (2006) Population Projections, Australia, 2004-2101. Australian Bureau of Statistics, Canberra

15. Australian Institute of Health and Welfare (2005) Grim books version 8. Available from http://www.aihw.gov.au, accessed 1 June 2007

16. Lipscombe LL, Hux JE (2007) Trends in diabetes prevalence, incidence, and mortality in Ontario, Canada 1995-2005: a population-based study. Lancet 369:750-756
17. Fox CS, Pencina MJ, Meigs JB, Vasan RS, Levitzky YS, D'Agostino RB Sr (2006) Trends in the incidence of type 2 diabetes mellitus from the 1970s to the 1990s: the Framingham Heart Study. Circulation 113:2914-2918

18. Briggs $\mathrm{AH}$ (2000) Handling uncertainty in cost-effectiveness models. Pharmacoeconomics 17:479-500

19. Narayan KM, Boyle JP, Thompson TJ, Gregg EW, Williamson DF (2007) Effect of BMI on lifetime risk for diabetes in the US. Diabetes Care 30:1562-1566

20. Burke JP, Williams K, Gaskill SP, Hazuda HP, Haffner SM, Stern MP (1999) Rapid rise in the incidence of type 2 diabetes from 1987 to 1996: results from the San Antonio Heart Study. Arch Intern Med 159:1450-1456

21. Knowler WC, Bennett PH, Hamman RF, Miller M (1978) Diabetes incidence and prevalence in Pima Indians: a 19-fold greater incidence than in Rochester, Minnesota. Am J Epidemiol 108:497-505

22. Bonora E, Kiechl S, Willeit J et al (2004) Population-based incidence rates and risk factors for type 2 diabetes in white individuals: the Bruneck study. Diabetes 53:1782-1789

23. Valdes S, Botas P, Delgado E, Alvarez F, Cadorniga FD (2007) Population-based incidence of type 2 diabetes in northern Spain: the Asturias Study. Diabetes Care 30:2258-2263

24. Cugati S, Wang JJ, Rochtchina E, Mitchell P (2007) Ten-year incidence of diabetes in older Australians: the Blue Mountains Eye Study. Med J Aust 186:131-135

25. Mooy JM, Grootenhuis PA, de Vries H et al (1996) Intra-individual variation of glucose, specific insulin and proinsulin concentrations measured by two oral glucose tolerance tests in a general Caucasian population: the Hoorn Study. Diabetologia 39:298-305

26. de Vegt F, Dekker JM, Stehouwer CD, Nijpels G, Bouter LM, Heine RJ (2000) Similar 9-year mortality risks and reproducibility for the World Health Organization and American Diabetes Association glucose tolerance categories: the Hoorn Study. Diabetes Care 23:40-44

27. Peeters A, Mamun AA, Willekens F, Bonneux L (2002) A cardiovascular life history. A life course analysis of the original Framingham Heart Study cohort. Eur Heart J 23:458-466

28. Breast Cancer Network Australia (2007) Latest facts and figures. Available from http://www.bcna.org.au, accessed 10 December 2007

29. Ward JE, Hughes AM, Hirst GH, Winchester L (1997) Men's estimates of prostate cancer risk and self-reported rates of screening. Med J Aust 167:250-253 